\title{
Prediction of liability to orofacial clefting using genetic and craniofacial data from parents
}

\author{
Peter A Mossey, Reynir Arngrimsson, John McColl, Gill M Vintiner, J Michael Connor
}

Department of Dental Health, University of Dundee Dental School, Park Place, Dundee DD1 4HR, UK

P A Mossey

\section{Department of} Medical Genetics, The University, Glasgow, UK

R Arngrimsson

J M Connor

\section{Department of} Statistics, The

University, Glasgow, UK

$\mathrm{J}$ McColl

Institute of Child Health, Guilford

Street, London, UK

G M Vintiner

Correspondence to: Dr Mossey.

Received 4 August 1997 Revised version accepted for publication

12 November 1997

\begin{abstract}
Background-Cleft lip with or without cleft palate (CL(P)) and isolated cleft palate (CP) are separate clinical entities and for both polygenic multifactorial aetiology has been proposed. Parents of children with orofacial clefting have been shown to have distinctive differences in their facial shape when compared to matched controls.
\end{abstract}

Objective-To test the hypothesis that genetic and morphometric factors predispose to orofacial clefting and that these markers differ for CL(P) and CP.

Methods-Polymorphisms at the transforming growth factor alpha (TGFa) locus in 83 parents of children with nonsyndromic orofacial clefts were analysed, and their craniofacial morphology was assessed using lateral cephalometry.

Results-Parents of children with CL(P) and CP showed an increased frequency of the TGFo/TaqI C2 allele (RR=4.10, $\mathrm{p}=0.009)$ relative to the comparison group. Also the TGFalBamHI A1 allele was more prevalent in the CP parents.

Multivariate statistical analysis-Using stepwise logistic regression analysis the TGFalTaqI C2 polymorphism provides the best model for liability to orofacial clefting. To determine the type of clefting a model involving interaction between the parental TGFa/BamHI and TGFalRsaI genotypes showed the best fit. Using genotype only to predict the clefting defect in the children according to parental genotype, $68.3 \%$ could be correctly classified. By adding information on craniofacial measurements in the parents, $76 \%$ of CP and $94 \%$ of CL(P) parents could be correctly classified.

Conclusions-This study provides a model for prediction of liability to orofacial clefting. These findings suggest that different molecular aberrations at the TGFa locus may modify the risk for $\mathrm{CP}$ and $\mathrm{CL}(\mathrm{P})$. (F Med Genet 1998;35:371-378)

Keywords: orofacial clefts; TGF $\alpha$; cephalometrics

Cleft lip with or without cleft palate (CL(P)) and isolated cleft palate (CP) are caused by primary defects in the fusion of craniofacial processes that form the primary and secondary palate respectively, but differ in respect to timing. Primary palate fusion takes place at about the fifth week of embryonic life by a highly regulated process of mesenchymal proliferation and epithelial breakdown in three facial prominences, the medial nasal, lateral nasal, and maxillary prominences, whereas elevation and fusion of the secondary palate occurs at about eight weeks. Furthermore, epidemiological and family studies indicate that $C L(P)$ and $C P$ are separate aetiological entities, ${ }^{1-3}$ and for both multifactorial inheritance has been proposed. The precise roles played by genes and environment has not been elucidated, in particular the nature and number of genes involved is not known. ${ }^{4-8}$ Thus in current medical practice genetic counselling is based on empirical figures which show recurrence risk, depending on the type of orofacial clefting found in the family, varying from $2-6 \%$ if one child or one parent is affected to $9 \%$ if two children are affected and $15-17 \%$ if a parent and a child both have clefts. ${ }^{2}$

Evidence for a genetic contribution comes from both human and animal studies. In humans, the importance of the TGF $\alpha$ locus in orofacial clefting has been highlighted in several studies, where association with polymorphisms within the TGF $\alpha$ gene locus has been shown. ${ }^{9-16}$ Possible interaction between polymorphisms of this gene and environmental factors such as smoking has also been suggested. ${ }^{78}$ The importance of TGF $\alpha$ is further indicated by gene expression studies in murine palatogenesis in mice where spatial and temporal expression of the gene is highly regulated during secondary palatogenesis. ${ }^{17}$

Fraser and Pashayan ${ }^{18}$ in 1970, and a number of others since then, ${ }^{19-23}$ have reported significant differences in parental cranial and facial shape compared to controls. They generally imply that the deviations from "normal" or control craniofacial morphology may represent the extreme limit of normal variability, and that the genes responsible for the deviation from normal contribute to the manifestation of clefting in their offspring. It is feasible, therefore, that cephalometric studies could enable the identification of phenotypes which could be used to identify people who possess the cleft lip/palate susceptibility genotype. In the quest for genetic predictors of orofacial clefting, most of the previous research effort has been focused on affected subjects. The contribution of heredity is acknowledged but the nature of this with respect to maternal and paternal contribution remains virtually unexplored. The aim of this study was to identify parental characteristics (phenotypic or genotypic) which were associated with an increased risk of having a child with $\mathrm{CL}(\mathrm{P})$ or $\mathrm{CP}$. 
Table 1 Composition of parental and control cephalometric and genetic study samples classified according to gender and clefting status

\begin{tabular}{|c|c|c|c|c|c|c|}
\hline \multirow[b]{3}{*}{ Subjects } & \multicolumn{3}{|c|}{ Cephalometric study } & \multicolumn{3}{|l|}{ Genetic study } \\
\hline & \multicolumn{2}{|l|}{ Parents } & \multirow[t]{2}{*}{ Control } & \multicolumn{2}{|l|}{ Parents } & \multirow[t]{2}{*}{ Control $^{\star}$} \\
\hline & $C P$ & $C L(P)$ & & $C P$ & $C L(P)$ & \\
\hline Female & 17 & 25 & 50 & 18 & 21 & - \\
\hline Male & 18 & 23 & 49 & 17 & 20 & - \\
\hline Totals (\%) & \multirow{2}{*}{\multicolumn{2}{|c|}{$48(37.8 \%)$}} & 99 & $35(45.3 \%)$ & $41(54.7 \%)$ & 62 \\
\hline All & & & 99 & \multicolumn{2}{|r|}{ (- } & 62 \\
\hline
\end{tabular}

* Gender ratio of genetic controls unknown.

\section{Methods}

SUBJECTS

The subjects in this study were the parents of a completely ascertained sample of 256 children with cleft lip/palate born in the west of Scotland between 1 January 1980 and 31 December 1984. The study sought only the parents of non-syndromic cases of both CL(P) and isolated CP. Ethical approval for the study was obtained. A careful history was taken to determine that the parents used were in fact the biological parents of the cleft proband. Parents of those with syndromic clefting as well as nonwhite and edentulous subjects were excluded, leaving 196 parental "pairs". All these parents were invited to participate and 136 replied. Of these 83 subjects, 40 fathers and 43 mothers attended the study clinic (table 1). No bias with respect to age and social class was apparent in the final study sample compared to the total sample.

The cephalometric control information was derived from evaluation of existing records from normal adult subjects among the archives of the Dental Hospital and School, Glasgow. ${ }^{23}$ The criteria used in the selection of this control group so as to match the parental sample as closely as possible were gender, age, racial background, previous dental history, and type of malocclusion. A total of 49 male and 50 female radiographs was used as the cephalometric control material.

\section{GENOTYPING}

DNA was extracted from lymphocytes using standard laboratory procedures ${ }^{24}$ and three polymorphisms within the TGF $\alpha$ gene, as previously described, ${ }^{25}$ were studied. Genotyping was carried out by DNA amplification at the TGF $\alpha$ locus using PCR and restriction endonuclease digestion using $B a m \mathrm{HI}, R s a \mathrm{I}$, and TaqI restriction enzymes. The BamHI polymorphism is situated in exon VI and detects a single nucleotide substitution allowing distinction between two alleles, $\mathrm{A} 1$ and $\mathrm{A} 2$. The RsaI and TaqI sites are both in intron V, the former created by a single base pair transition showing the two alleles B1 and B2, whereas the latter restriction site represents a four base pair deletion, $\mathrm{C} 1$ representing the insertion and $\mathrm{C} 2$ the deletion. The three sets of alleles were visualised by subjecting the digested PCR products to horizontal electrophoresis on a $2.5 \%$ agarose gel.

In the absence of genetic control data for the west of Scotland population, the control data for the present study were derived from the UK study by Holder et al. ${ }^{11}$ Use of such data can be justified by the fact that allele frequency at the TGF $\alpha$ locus in control subjects in populations as diverse as Australia, America, and Britain were found to be remarkably similar (table 2 ).

\section{CEPHALOMETRIC MEASUREMENT}

Measurements of the craniofacial parameters in the parental and control radiographs was carried out by the same investigator (PAM) without knowledge of the status of the subject. Cephalometric tracings of the lateral cephalograms were prepared on acetate overlays. Subsequent digitisation was performed on a GTCO Company backlit digitising screen using a digipad 5 digitiser. The PC DIG software program was used to compute the desired parameters and individual, mean, and superimposed tracings were produced using a Hewlett Packard ColorPro printer. (The computer software program used in this study was devised by Dr John McWilliam, Karolinska Institute, Stockholm, Sweden, 1987.) Measurements were verified by double digitisation of all the radiographs and repeated tracing of $20 \%$ of the material as recommended by Houston. ${ }^{26}$ The PC DIG program allowed measurement of cephalometric areas and, in the context of the present study, six separate

Table 2 TGFa allele frequencies from previous population controls

\begin{tabular}{|c|c|c|c|c|c|c|}
\hline \multirow[b]{2}{*}{ Reference } & \multicolumn{6}{|c|}{ Allele frequency } \\
\hline & $A 1$ & $A 2$ & $B 1$ & $B 2$ & $C 1$ & $C 2$ \\
\hline (1) Murray et al & 0.190 & 0.810 & 0.290 & 0.710 & 0.940 & 0.060 \\
\hline (2) Ardinger et al & 0.130 & 0.870 & 0.270 & 0.730 & 0.950 & 0.050 \\
\hline (3) Chenevix-Trench et $a l^{10}$ & - & - & - & - & 0.945 & 0.055 \\
\hline (4) Holder et $a l^{\star 11}$ & 0.130 & 0.870 & 0.360 & 0.640 & 0.960 & 0.040 \\
\hline (5) Qian et $a l^{5}$ & 0.076 & 0.924 & 0.293 & 0.707 & 0.930 & 0.070 \\
\hline (6) Sassani et $a^{14}$ & - & - & 0.262 & 0.738 & 0.911 & 0.089 \\
\hline
\end{tabular}

Control characteristics

(1) American whites, $n=69$

(2) American whites, $n=102$.

(4) British whites, $n=62$.

3) Australian whites, $n=100$ 
Table 3 Number of chromosomes with each allele in the $C P, C L(P)$, and control group and the relative risk associated with these TGFa polymorphisms

\begin{tabular}{|c|c|c|c|c|c|c|}
\hline & & $\begin{array}{l}\text { No of } \\
\text { alleles }\end{array}$ & & $R R(95 \% C I)$ & $\chi^{2}$ & $p$ value \\
\hline \multirow[t]{5}{*}{ BamHI } & & A1 & A2 & & & \\
\hline & Control & 16 & 104 & & & \\
\hline & $\mathrm{CP}$ & 15 & 45 & $2.17(1.00-4.71)$ & 3.82 & 0.05 \\
\hline & $\mathrm{CL}(\mathrm{P})$ & 6 & 68 & $0.57(0.36-1.32)$ & 1.24 & 0.26 \\
\hline & All parents & 21 & 113 & $1.21(0.61-2.14)$ & 0.27 & 0.60 \\
\hline \multirow[t]{5}{*}{ RsaI } & & B1 & B2 & & & \\
\hline & Control & 42 & 78 & & & \\
\hline & $\mathrm{CP}$ & 18 & 40 & $0.81(0.42-1.59)$ & 0.36 & 0.55 \\
\hline & $\mathrm{CL}(\mathrm{P})$ & 25 & 49 & $0.92(0.50-1.70)$ & 0.07 & 0.79 \\
\hline & All parents & 43 & 89 & $0.87(0.52-1.48)$ & 0.25 & 0.61 \\
\hline \multirow[t]{5}{*}{$\operatorname{Taq} \mathrm{I}$} & & $\mathrm{Cl}$ & $\mathrm{C} 2$ & & & \\
\hline & Control & 115 & 5 & & & \\
\hline & $\mathrm{CP}$ & 53 & 9 & $3.91(1.33-11.45)$ & 6.17 & 0.01 \\
\hline & $\mathrm{CL}(\mathrm{P})$ & 68 & 10 & $3.38(1.17-9.78)$ & 5.06 & 0.02 \\
\hline & All parents & 121 & 19 & $3.61(1.38-9.48)$ & 6.82 & 0.01 \\
\hline
\end{tabular}

Relative risk (RR) and $95 \%$ confidence interval $(95 \% \mathrm{CI})$ as the odds ratio in the parental sample compared with the control sample for alleles $\mathrm{A} 1, \mathrm{~B} 1$, and $\mathrm{C} 2$.

area measurements were chosen to augment the linear and angular cephalometric analysis devised. ${ }^{27}$ In order to delineate and compute areas on a lateral cephalogram using the PC DIG program, perimeter landmarks of the structures to be investigated were digitised sequentially. Area was automatically calculated in square centimetres.

The choices of linear, angular, and area measurements used in this study were based on the need to describe comprehensively all anatomical regions of the head and face, avoiding the use of parameters that were highly correlated with each other, and where possible landmarks were chosen on the basis of reliability. ${ }^{27}$ Thirty seven independent variables were used in the study to achieve a comprehensive description of all parts of the craniofacial skeleton. Full details on how craniofacial parameters were chosen and adjusted for multivariate discriminant analysis are described in Mossey et al. ${ }^{27}$

\section{STATISTICAL ANALYSES}

Comparison between allele and genotype frequencies was performed using the chisquared test and the relative risk estimation was calculated as odds ratio devised by Woolf. ${ }^{28}$ The two sample $t$ test was used to estimate the difference in craniofacial measurements between the parental and control samples. Significance levels ( $p$ values) were corrected for multiple testing. One way analysis of variance (ANOVA) was used to estimate which of the cephalometric parameters gave best discrimination between parents of $C P$ and $C L(P)$ patients. Multivariate stepwise discriminant analysis was used to identify those cephalometric parameters found to be most useful to discriminate between the study groups. Logistic regression models were used to determine the relationship between genotypes and liability to orofacial clefting. The factors introduced into the models were the status, as parent of a child with orofacial clefting or a normal control subject. Secondly, the genotypes representing the three polymorphisms for each of these subjects were entered in a stepwise manner each as a separate factor. A forward stepwise approach was adopted and a lattice of hypotheses produced. The resulting logistic regression has a chi-squared statistic distribution. A second logistic regression model was set up in the same way to determine which of the following factors, parental status and the three TGFa genotypes, would best discriminate between a parent predisposed towards producing a child with $C P$ rather than $C L(P)$. Finally, cephalometric variables found to be significantly different by the ANOVA analysis in the CP compared to the CL(P) parental sample were introduced to the second model with and without the genetic data.

As indicated above, it was possible to carry out a comparison of cephalometric and genotypic differences between parents of children with CP versus CL(P) and of each cleft sample with their respective control groups. However, a joint analysis of the genetic and morphometric variations was not possible in this study because the control subjects for each comparison were not the same subjects.

\section{Results}

ALLELE AND GENOTYPE FREQUENCIES

Study of the allele frequencies showed a significant difference in the prevalence of the $\mathrm{C} 2$ allele of the TGF $\alpha / T a q I$ polymorphism among parents of patients with orofacial clefting compared to the control group $(R R=3.61, p<0.01)$ (table 3). This was found in both the CP (3.91, $\mathrm{p}<0.01)$ and the $\operatorname{CL}(\mathrm{P})(3.38, \mathrm{p}<0.02)$ parental sample. When the allele distribution at the $B a m \mathrm{HI}$ and RsaI TGF $\alpha$ gene restriction sites were investigated no significant difference in allele frequencies was observed between case parents and controls. The prevalence of the A1 allele of the BamHI polymorphism was, however, slightly increased in the CP parental sample $(R R=2.75, p<0.05)$ (table 4).

Further studies showed contrasting differences in the genotypes in these samples. The C2 allele was found to be rare in both parental samples and the control sample. Only two subjects were found to be homozygous for this allele and both of these were fathers of a child with $C L(P)$. There was a significantly higher prevalence of the C2 allele, in either the homozygous or heterozygous state, in both parents of $C L(P)$ patients $(R R=3.79, p<0.05)$ and parents of children born with isolated $C P(R R=4.50, p<0.01)$ (table 4). Only in the CP parental group was an increased prevalence of the A1 allele found among heterozygous or homozygous subjects $(R R=2.75, p<0.03)$. When the genotype frequencies were compared in the CP and CL(P) groups, a difference in the prevalence of the $\mathrm{Al}$ allele was observed. The parents of CP patients were found to have a significantly higher prevalence of the A1 allele and A1A2 genotype than the $\operatorname{CL}(P)$ group $\left(\chi^{2}=7.29, p=0.003\right)$.

When the genotype pattern in respect to the $B a m \mathrm{HI}$ and RsaI sites were compared, parents of CP patients were found to have predominantly the A1A2/B1B2 genotype (12/14), while parents of children with CL(P) had predominantly the A2A2/B1B2 genotype (13/17). In the control group the distribution of these combined genotypes was A1A2/B1B2 $(n=12$, $52 \%)$ and the A2A2/B1B2 ( $n=11,48 \%)$ (table 7). Applying the chi-squared statistic, a 
Table 4 Genotype distribution for BamHI, RsaI, and TaqI alleles and relative risk (RR) associated with possession of the TGFa BamHI A1 or TaqI C2 alleles in parents of children with orofacial clefts compared to control subjects

\begin{tabular}{|c|c|c|c|c|c|c|c|}
\hline & \multirow[b]{2}{*}{$A 1 A 1$} & \multirow[b]{2}{*}{$A 1 A 2$} & \multirow[b]{2}{*}{$A 2 A 2$} & \multicolumn{2}{|c|}{ Relative risk ( $R$ ) } & \multirow[b]{2}{*}{$\chi^{2}$} & \multirow[b]{2}{*}{$p$ value } \\
\hline & & & & $A 1 A 2$ & $95 \% C I$ & & \\
\hline \multicolumn{8}{|l|}{ (A) BamHI genotypes } \\
\hline CP & 0 & 15 & 15 & 2.75 & $1.11-6.78$ & 4.82 & $0.028^{\star}$ \\
\hline $\mathrm{CL}(\mathrm{P})$ & 0 & 6 & 31 & 0.53 & $0.19-1.50$ & 1.42 & 0.23 \\
\hline All clefts & 0 & 21 & 46 & 1.26 & $0.58-2.71$ & 0.04 & 0.56 \\
\hline \multirow[t]{2}{*}{ For A1A2 CP $v \mathrm{CL}(\mathrm{P})$} & & & & & & 7.29 & $0.003^{\star \star}$ \\
\hline & B1B1 & B1B2 & B2B2 & & & & \\
\hline \multicolumn{8}{|l|}{ (B) RsaI genotypes } \\
\hline Holder et al ${ }^{11}$ & 10 & 22 & 27 & & & & \\
\hline CP & 2 & 13 & 14 & & & 1.74 & 0.42 \\
\hline $\mathrm{CL}(\mathrm{P})$ & 4 & 15 & 19 & & & 0.78 & 0.68 \\
\hline \multirow[t]{2}{*}{ All clefts } & 6 & 28 & 33 & & & 1.82 & 0.40 \\
\hline & $\mathrm{ClCl}$ & $\mathrm{C} 1 \mathrm{C} 2$ & $\mathrm{C} 2 \mathrm{C} 2$ & $\mathrm{C} 2 \dagger$ & & & \\
\hline \multicolumn{8}{|l|}{ (C) TaqI genotypes } \\
\hline Holder $e t$ al $^{11}$ & 55 & 5 & 0 & & & & \\
\hline $\mathrm{CP}$ & 22 & 9 & 0 & 4.50 & $1.40-14.02$ & 6.73 & $0.009^{\star \star}$ \\
\hline $\mathrm{CL}(\mathrm{P})$ & 29 & 8 & 2 & 3.79 & $1.25-11.55$ & 6.35 & $0.04^{\star}$ \\
\hline All clefts & 51 & 17 & 2 & 4.10 & $1.50-11.18$ & 7.76 & $0.02^{\star}$ \\
\hline
\end{tabular}

Homozygosity for $\mathrm{C} 2 \mathrm{C} 2: \chi^{2}=1.55 ; \mathrm{p}=0.21$.

$\chi^{2}$ repeated with $\mathrm{C} 1 \mathrm{C} 2$ and $\mathrm{C} 2 \mathrm{C} 2$ combined in one group:

(i) $\mathrm{CP}: \chi^{2}=5.23 ; \mathrm{p}=0.022^{\star}$

(ii) $\mathrm{CL}(\mathrm{P}): \chi^{2}=5.51 ; \mathrm{p}=0.019^{\star}$

(iii) All clefts: $\chi^{2}=7.34 ; \mathrm{p}=0.006^{\star \star}$

$\star \star \mathrm{p}<0.01,{ }^{\star} \mathrm{p}<0.05$

†Relative risk for possession of $\mathrm{C} 2$ allele with $\mathrm{C} 1 \mathrm{C} 2$ and $\mathrm{C} 2 \mathrm{C} 2$ combined in one group

significant difference between parental and control groups was observed $\left(\chi^{2}=11.89\right.$, $\mathrm{p}<0.001)$. All of the variation producing this difference is in the BamHI polymorphism.

The parental distribution of alleles was studied further by looking at the fathers and mothers separately. The TGF $\alpha / B a m H I$ Al allele was found significantly more often among mothers $(16 / 60)$ compared to the fathers $(5 / 53)$ $\left(\chi^{2}=3.86, p<0.05\right)$ and this variance could be attributed to differences among parents of $C L(P)$ patients rather than those of $C P$. In the $C L(P)$ group, none of the fathers possessed a genotype with this allele (A1A2 or A1A1), so for an offspring with $C L(P)$ the $A 1$ allele was always transmitted from the mother. It was also noted that when the father had transmitted the A1 allele to his affected child $(n=5)$ the outcome was always an offspring with isolated $\mathrm{CP}$, but with such small numbers this needs to be interpreted with caution.

CEPHALOMETRIC MEASUREMENTS

To compare the cranial and facial shape of parents and control subjects, 37 cephalometric parameters were measured in males and females and the data were analysed separately using the two sample $t$ test. The fathers of children with orofacial clefts were shown to have significantly smaller mandibular, symphyseal, and maxillary areas on lateral skull radiographs and reduction in palatal length (ANS-PNS) (table 5, fig 1). In addition, the cranial base angle (N-S-Ba) was more acute and although the cross sectional area of the cranium was smaller in the fathers compared to the control males the occipital subtenuce was larger (table 5, fig 1). Using stepwise discriminant analysis, $83.3 \%$ of fathers were correctly classified as being at risk for having a child with orofacial clefting. The mothers had larger anterior facial height (N-Gn) and total facial length (S-Gn). The anterior cranial base (N-S) and the clivus length (S-Ba) were also larger than in the control females (table 5, fig 1). As in the paternal group, reduced cross sectional area of the cranium and increase in the occipital subtenuce length was observed. Using these parameters in a stepwise discriminant analysis $95.1 \%$ of mothers were correctly classified as being at risk for having a child with orofacial clefting.

Table 5 Craniofacial measurements found to be significantly different between parents of children with orofacial clefting and controls using two sample t test

\begin{tabular}{lcccc}
\hline Variable & Cases & Controls & $(95 \%$ CI $)$ & $p$ value \\
\hline Males & $n=47$ & $n=49$ & $(0.22,0.59)$ & 0.0001 \\
Area-symphysis $\left(\mathrm{cm}^{2}\right)$ & $3.1 \pm 0.4$ & $3.6 \pm 0.4$ & $(1.20,3.95)$ & 0.0003 \\
Area-mandible $\left(\mathrm{cm}^{2}\right)$ & $30.1 \pm 3.4$ & $33.1 \pm 3.1$ & $(0.17,0.72)$ & 0.0015 \\
Area-maxilla $\left(\mathrm{cm}^{2}\right)$ & $3.9 \pm 0.7$ & $4.5 \pm 0.5$ & $(0.68,3.40)$ & 0.0037 \\
ANS-PNS $(\mathrm{mm})$ & $51.4 \pm 3.9$ & $53.1 \pm 2.8$ & $(8.5,20.7)$ & $<0.001$ \\
Area-cranium $\left(\mathrm{cm}^{2}\right)$ & $219.9 \pm 14.3$ & $235.2 \pm 16.0$ & $(-4.25,-0.08)$ & 0.04 \\
Occipital subtenuce (mm) & $30.7 \pm 4.2$ & $28.8 \pm 4.5$ & $(-4.44,-0.58)$ & 0.011 \\
Females & $n=47$ & $n=50$ & $(-4.87,-0.16)$ & 0.036 \\
Mandibular length (mm) & $106.4 \pm 4.7$ & $104.2 \pm 4.8$ & $(-4.92,-0.91)$ & 0.005 \\
Anterior face height $(\mathrm{mm})$ & $108.2 \pm 5.1$ & $106.6 \pm 5.9$ & $(-2.56,-0.27)$ & 0.016 \\
Facial length (mm) & $113.4 \pm 5.1$ & $111.2 \pm 5.0$ & $(-2.35,-0.10)$ & 0.033 \\
Anterior cranial base $(\mathrm{mm})$ & $64.5 \pm 3.0$ & $63.3 \pm 2.4$ & $(-0.92,-0.00)$ & 0.048 \\
Clivus length (mm) & $42.4 \pm 2.0$ & $41.3 \pm 3.1$ & $(6.1,17.10)$ & 0.0001 \\
Sella width $(\mathrm{mm})$ & $10.1 \pm 0.9$ & $9.7 \pm 1.2$ & $(-5.33,-1.90)$ & 0.0001 \\
Area-cranium $\left(\mathrm{cm}^{2}\right)$ & $203.5 \pm 14.1$ & $216.4 \pm 12.2$ & & \\
Occipital subtenuce $(\mathrm{mm})$ & $29.5 \pm 3.3$ & $25.8 \pm 4.3$ & & \\
\hline
\end{tabular}




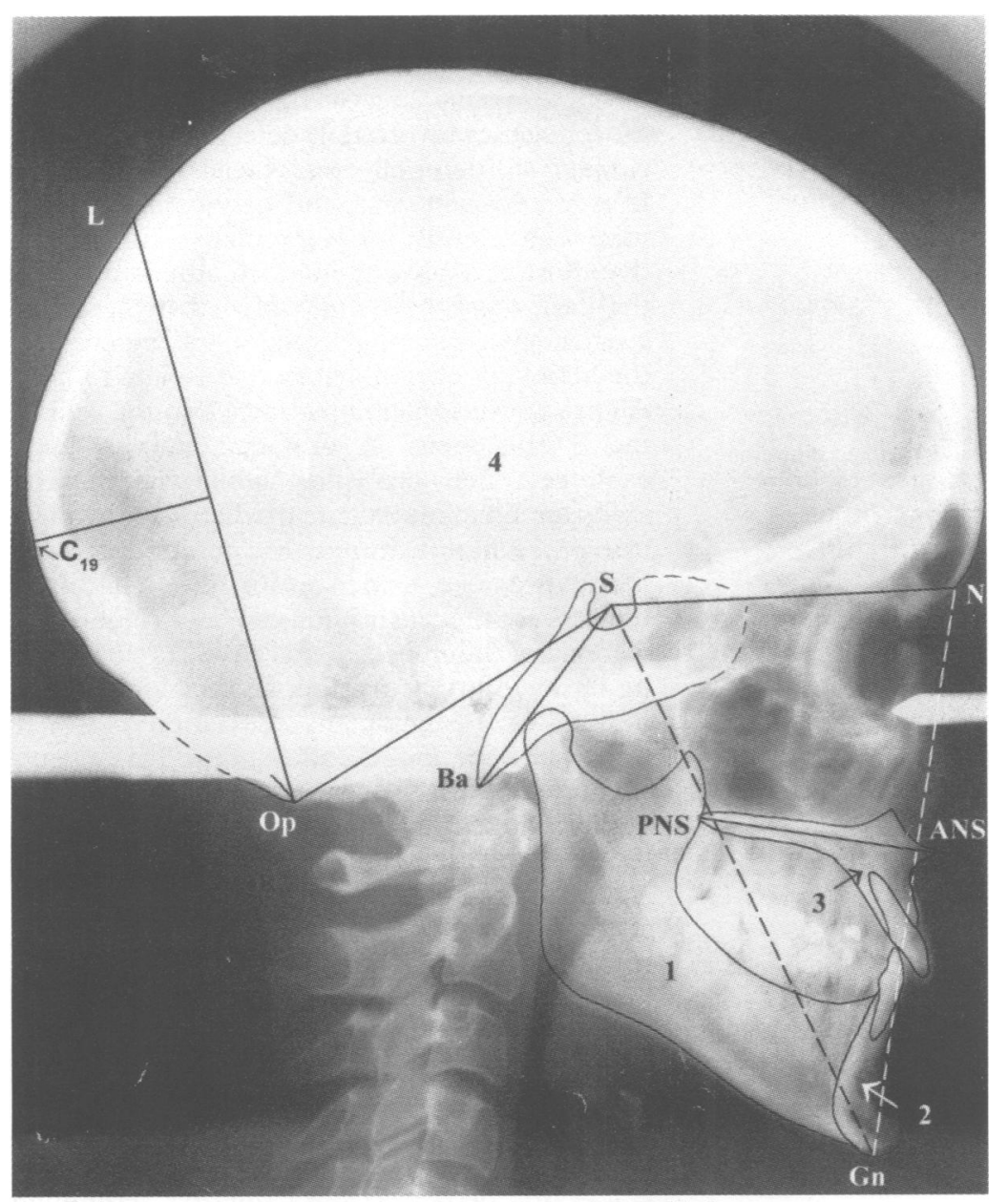

Fathers

\section{$\downarrow$ Mandibular area (1)}

$\downarrow$ Symphyseal area (2)

$\downarrow$ Maxillary area (3)

$\downarrow$ Palatal length ( ANS - PNS

$\downarrow$ Cranial base angle ( N-S-Ba)

$\downarrow$ Cranial area (4)

$\uparrow$ Occipital subtenuce ( to $C_{19}$ )

- Occipital subtenuce is a measure of the longest distance subtended by a perpendicular from the occipital chord (measured from the lambdoid suture (L) to opisthion (Op)) to the outline of the occipital cranium.

Figure 1 Lateral skull cephalogram illustrating the cephalometric parameters which were significantly different in fathers and mothers compared to controls.

To identify which of the cephalometric parameters could best distinguish between parents having a child with $\mathrm{CP}$ and those with a child with $\mathrm{CL}(\mathrm{P})$, a three group $(\mathrm{CP}, \mathrm{CL}$, and CLP), one way analysis of variance (ANOVA) was carried out by comparing the results from the cephalometric measurements in these three groups. Not one parameter differed between the CLP and CL groups. However, three parameters, the mandibular ramus length, mandibular area, and cranial area, turned out to be significantly larger in CP parents compared to $\mathrm{CL}(\mathrm{P})$ parents (table 6 ).

Table 6 Cephalometric parameters which show a significant difference between parents of children with $C P$ and $C L(P)$

\begin{tabular}{lcccl}
\hline Parameter & $C P$ & $C L(P)$ & $95 \% C I$ & $p$ value \\
\hline Mandibular & $31.13 \pm 3.09$ & $29.77 \pm 2.82$ & $0.03-2.67$ & $0.045^{\star}$ \\
Area $\left(\mathrm{cm}^{2}\right)$ & $68.70 \pm 4.57$ & $65.67 \pm 4.38$ & $1.04-5.02$ & $0.0033^{\star \star}$ \\
Ramus length $(\mathrm{mm})$ & Cranium & $208.5 \pm 6.6$ & $0.006-0.06$ & $0.018^{\star}$ \\
Area $\left(\mathrm{cm}^{2}\right)$ & $214.9 \pm 0.6$ & & \\
\hline
\end{tabular}

Table 7 BamHI/Rsal genotype interaction for $C P, C L(P)$, and control groups

\begin{tabular}{|c|c|c|c|}
\hline \multirow[b]{2}{*}{ Genotype } & \multicolumn{3}{|l|}{$B 1 B 2$} \\
\hline & $C P$ & $C L(P)$ & Control \\
\hline A1A2 & 12 & 4 & 12 \\
\hline A2A2 & 2 & 13 & 11 \\
\hline BamHI/RsaI interaction & $\chi^{2}$ & $p$ value & \\
\hline CP $v$ control & 4.30 & $0.038^{\star}$ & \\
\hline $\mathrm{CL}(\mathrm{P}) v$ control & 3.34 & 0.067 & \\
\hline $\mathrm{CP} v \mathrm{CL}(\mathrm{P})$ & 11.89 & $0.0006^{\star \star \star}$ & \\
\hline
\end{tabular}

$\star=\mathrm{p}<0.05$.

$\star \star \star=p<0.001$

LIABILITY MODELS USING GENOTYPIC DATA

The first logistic regression model to determine the relationship between the parental genotypes and the liability to have a child with clefting (either CP or CL(P)) was set up. The factors used were the TGF $\alpha$ genotypes produced by the BamHI, RsaI, and TaqI restriction enzymes and the parental gender. With this model forward stepwise approach was adopted and a lattice of hypotheses created. The effect of TaqI genotypes, either homozygous for the $\mathrm{C} 2$ allele or heterozygous (that is, C1C2), were entered first and this was shown to be the best discriminating factor in predicting the risk of having a child with orofacial clefts (CP or $\mathrm{CL}(\mathrm{P})$ ). There was only one subject in the entire study homozygous for this allele, and in the heterozygous state there were 17 out of 51 parents and five out of 60 controls. On the basis of the $\mathrm{C} 2$ allele alone as a discriminator, therefore, $33 \%$ of parents would be correctly classified as being predisposed to having orofacial clefting in their offspring, whereas $8 \%$ of controls would be wrongly classified. This is in line with previous observations on the $T G F \alpha$ gene, that it is a modifier gene rather than a major gene in the aetiology of orofacial clefting.

A second logistic regression model was set up to determine which of the genotypes with or without consideration of parental gender would best discriminate between parents predisposed towards producing a child with $\mathrm{CP}$ or CL(P). This indicated that an interaction between $B a m \mathrm{HI}$ and $R s a \mathrm{I}$ genotypes should be introduced into the model. For the combined parental genotype A1A2/B1B2, the outcome is predominantly a child with CP $(12 / 14)$, while the genotype $\mathrm{A} 2 \mathrm{~A} 2 / \mathrm{B} 1 \mathrm{~B} 2$ predisposed to $\mathrm{CL}(\mathrm{P})(13 / 17)$ (table 7).

To investigate the influence of parental morphometric data on the discriminative ability of this second model, three cephalometric measurements found to distinguish best between parents with CP children and those having $\mathrm{CL}(\mathrm{P})$ children were entered into the model. This showed an improvement in the prediction values as $76 \%$ of $C P$ parents and $94 \%$ of $C L(P)$ parents could be correctly classified. The same three cephalometric variables were then entered into the logistic regression model in the same order without the genetic variables. This resulted in a reduction in the discriminative power of the model for CL(P) status from $94 \%$ to $78 \%$, while for CP the prediction $(72 \%)$ was only slightly reduced. This indicates the comparatively greater importance of genetic factors 


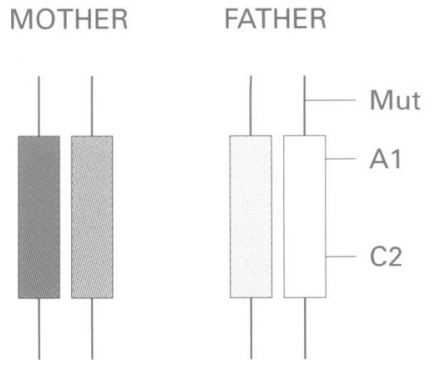

The father has the TGF $\alpha$ risk haplotype and the associated mutation. Transmission of normal TGF $\alpha$ protein across the placenta during palatogenesis rescues the merging of the primary palate.

CHILD

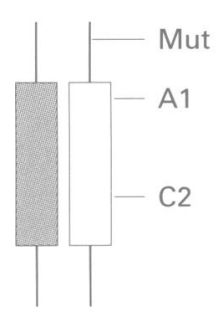

The child has inherited a polygenic background from both parents making it susceptible for developing orofacial clefts including the risk haplotype at the TGF $\alpha$ locus from the father. The child is thus unable to express this molecule during primary palatogenesis. The maternal rescue influences the merging of the primary palate but not the fusion of the secondary palate and the child develops isolated cleft palate (CP).

Figure 2 The influence of polymorphisms at the TGFa locus on the type of cleft (CP or $C L(P))$ explained by a maternal rescue model.

apart from possible morphogenetic ones in the aetiology of $\mathrm{CL}(\mathrm{P})$.

\section{Discussion}

Analysis of cephalometric craniofacial parameters in this study confirms that distinctive differences do exist between the parents of children with clefting deformities and controls. Furthermore, there are differences between the parents of $\mathrm{CP}$ children and those of $\mathrm{CL}(\mathrm{P})$ children with regard to craniofacial morphology.

This study indicates that polymorphisms at the TGF $\alpha$ locus shown by TaqI enzyme digestion (the C1, C2 alleles) predict the likelihood of a person in the population having a child with a cleft defect per se. Furthermore, digestion with $B a m \mathrm{HI}$ (producing A1, A2 alleles) enables discrimination between the likelihood of that birth defect being a CP or CL(P). The discrimination between the two types of birth defect can be further sharpened by incorporating cephalometric data. Three craniofacial parameters have been identified by this study as being particularly useful for this purpose. This represents a considerable simplification of the cephalometric analysis proce- dure normally required for analysis of craniofacial form.

These results suggest that there are certain morphogenes involved in determining the cleft susceptible parental craniofacial morphology. It is noteworthy that the genotypic markers were consistently more predictive for $\mathrm{CL}(\mathrm{P})$ than for CP. This is in line with other studies in the past which have concluded that there is a greater environmental component involved in the aetiology of non-syndromic isolated CP. ${ }^{12}$ All previous association studies into the role of the TGF $\alpha$ locus in orofacial clefting have examined cleft probands, while the present study aimed to investigate predictors of liability using parental features. Examining parental DNA provides evidence for the hereditary nature of the gene defects and highlights distinctive differences between $\mathrm{CL}(\mathrm{P})$ and $\mathrm{CP}$ in terms of transmission at this locus. The finding of a significant association between CL(P) and the TaqI C2 allele of the TGF $\alpha$ gene is consistent with previous studies. ${ }^{7-121415}$ Only one previous study looked exclusively at the TGF $\alpha$ locus in an isolated CP sample ${ }^{13}$ and the significant association between the TaqI C2 allele reported in their sample of 52 patients was reproduced in the present parental study. The present study is the first to report a significant association between CP and the BamHI Al allele, although Ardinger $e t a l^{\prime}$ did report an association between CL(P) probands and the same A1 allele, as did Stoll et $a l^{12}$ in a sample of bilateral $C L(P)$ probands. The contrasting differences in the prevalence of the $\mathrm{BamHI}$ genotype found among parents of CP and CL(P) patients has not been described before.

The parental origin of the molecular aberration may also be important. The preliminary observation made in this study that the BamHI genotype A1A2 is only found among fathers of children with $C P$ and mothers with $C L(P)$ will need further investigation, but this preliminary study supports a maternal rescue hypothesis in the development of orofacial clefting. ${ }^{29}$ If the parents have transmitted polygenic predisposing mutations for orofacial clefting to the offspring and either of them is a carrier of a modifying molecular aberration associated with the A1A2 genotype and the C2 allele, the effect of transmission of this allele and the associated molecular aberration may be influenced by the parental gender. For example, if the father is the transmitting parent the outcome could be modified by maternal rescue in the form of normal maternal protein being transferred over the placenta (fig 2). This would result in an isolated $C P$, while if the mother was the transmitting carrier the maternal protein would also be defective, the maternal rescue would fail, and a different defect, that is CL(P), would be found in the child. The first step to test this hypothesis would be to perform a transmission disequilibrium test ${ }^{30}$ and haplotype relative risk analysis ${ }^{3132}$ on a larger data set which includes parents and offspring with orofacial clefts.

This study for the first time provides tangible morphometric and genetic evidence for a distinctive difference between the two types of 
orofacial clefting at a locus selected because of the temporal and spatial expression of its protein product during murine palatogenesis. Transforming growth factors (including TGFa) are suspected of playing a crucial role in human craniofacial morphogenesis and the finding of cephalometric differences between the parents of children with orofacial clefting and a control implies that these "craniofacial microforms" confer susceptibility. Identification of the sites of the craniofacial skeleton that characterise predisposition to $\mathrm{CP}$ and $\mathrm{CL}(\mathrm{P})$ might also provide clues as to the pathogenetic mechanisms involved in orofacial clefting.

\section{FUTURE STUDIES}

It is important to appreciate the subtlety of these craniofacial morphometric differences. While this study and a number of previous studies have reported statistically significant differences between the parents of children with orofacial clefting and a matched control, these differences tend to be small and often no greater than the variation in the normal population. It is also widely recognised that conventional cephalometric analysis using lines and angles is a crude morphometric instrument. As such it would be misleading to suggest that these parental cephalometric differences alone are sufficient to be of diagnostic value in predicting risk of orofacial clefting. This problem might, however, be overcome by the use of techniques which can measure shape differences such as Procrustes, thin plate spline, and finite element analysis. ${ }^{33}$ These techniques could concentrate on identification of morphometric differences in areas where previous studies suggest the differences lie.

Much larger samples, preferably obtained through multicentre collaboration, are required for meaningful and statistically powerful data even when these are subdivided for analysis into cleft type and gender. Consistency of association between studies carried out in populations with varying genetic backgrounds, lifestyles, and environmental exposures is an important criterion in judging whether an association is causal. It may also be that the morphometric hypothesis suggesting craniofacial shape predisposes to orofacial clefting is too unidimensional in the implication of cause and effect. There may well be a morphogenetic factor but the morphometric manifestation may not be a consistent one, even within the same population group, as other genetic and environmental factors are also operating.

The evidence from the present and previous studies $^{8-16}$ collectively indicates that the TGFa locus undoubtedly contributes towards the liability to orofacial clefting. It is, however, more likely to be a modifier gene rather than a major aetiological gene and other genetic factors are important. Future morphological and genetic studies will aim to establish further predisposing markers for both $\mathrm{CP}$ and $\mathrm{CL}(\mathrm{P})$. This study may present a model for investigating the role and possible interaction of candidate genes involved in the fusion of both the primary and secondary palate in the devel- opment of orofacial clefting, as well as their interaction with environmental risk factors. It will also be necessary to investigate phenotypic/ genotypic correlations in both CP and CL(P) groups in the expectation that this will further the present state of knowledge on the aetiopathogenesis of orofacial clefting. The evidence would seem to indicate that morphogenes responsible for the distinctive parental craniofacial morphology may also be predisposing to orofacial clefting in the offspring.

The information gained from the study of liability not only offers an improvement in the accuracy of genetic counselling to prevent recurrence, but also the possibility of identification of genetically susceptible subjects. Since orofacial clefting is a polygenic multifactorial disorder, subsequent research will need to be directed towards (1) improving knowledge about the role of environmental teratogens and (2) understanding the role of genetic susceptibility to environmental factors, that is, gene/environment interaction. Identification of genetically susceptible subjects and knowledge of the relevant environmental teratogens would assist in the planning of interventions in the periconceptional period making prevention of orofacial clefting theoretically possible. The help and contribution of Mrs Betty O'Hare, Medical
Genetics Department, Glasgow is gratefully acknowledged. Reynir Arngrimsson is a Wellcome Trust Research Fellow.

1 Fogh-Andersen P. Inheritance of harelip and cleft palate: contribution to the elucidation of the aetiology of the congenital clefts of the face. Copenhagen: Busck, 1942 .

2 Fraser FC. The genetics of cleft lip and palate. Am f Hum Genet 1970;22:336-52.

3 Mossey PA. An investigation of heredity in the aetiology and pathogenesis of cleft palate and of cleft lip and palate. $\mathrm{PhD}$ thesis, University of Glasgow, 1994.

4 Marazita ML, Spence MA, Melnick M. Major gene determination of liability to cleft lip with or without cleft palate. A multiracial view. 7 Craniofac Genet Dev Biol Suppl 1986;2:89-97.

5 Chung CS, Beechert AM, Lew RE. Test of heterogeneity of cleft lip with or without cleft palate as related to race and

6 Hecht JT, Wang Y, Blanton SH, Michels VV, Daiger SP. Cleft lip and palate: no evidence of linkage to transforming growth factor alpha. Am f Hum Genet 1991;48:1012-13.

7 Hwang SJ, Beaty TH, Panny SR, et al. Association study of $T G F a$ TaqI polymorphism and oral clefts: indication of gene-environment interaction in a population based sample of infants with birth defects. Am $\mathcal{F}$ Epidemiol 1995;141:62936.

8 Shaw GM, Wasserman CR, Lammer EJ, et al. Orofacial clefts, parental cigarette smoking and transforming growth factor alpha gene variants. Am $\mathcal{F}$ Hum Genet 1996;58:55161 .

9 Ardinger HH, Buetow KH, Bell GI, Bardach J, VanDemark DR, Murray JC. Association of genetic variation of the transforming growth factor alpha gene with cleft lip and transforming growth factor alpha gene with

10 Chenevix-Trench G, Jones K, Green A, Martin N. Further Chenevix-Trench G, Jones K, Green A, Martin N. Further
evidence for an association between genetic variation in transforming growth factor alpha and cleft lip and palate. Am f Hum Genet 1991;48:1012-13.

11 Holder SE, Vintiner GM, Farren B, Malcolm S, Winter RM. Confirmation of an association between RFLPs at the transforming growth factor alpha locus and non-syndromic cleft lip and palate. F Med Genet 1992;29:390-2.

12 Stoll C, Qian JF, Feingold J, Sauvage P, May E. Genetic variation in transforming growth factor alpha: possible association of $B a m \mathrm{HI}$ polymorphism with bilateral sporadic cleft lip and palate. Am $\mathcal{f}$ Hum Genet 1992;50:870-1.

13 Shiang R, Lidral AC, Ardinger $\mathrm{HH}$, et al. Association of transforming growth factor alpha et Association of transforming growth factor alpha gene polymorphisms with nonsyndromic cle

14 Sassani R, Bartlett SP, Feng $\mathrm{H}$, et al. Association between alleles of the transforming growth factor alpha locus and the occurrence of the cleft lip. Am $\mathscr{f}$ Med Genet the occurrence

15 Mossey PA, Arngrimmson R, Vintiner GM. Genotypic markers for orofacial clefting in the West of Scotland. Eur $\mathcal{F}$
Orthod 1995;14:346. 
16 Jara L, Blanco R, Chiffelle I, Palomino H, Carrero $H$. Association between alleles of the transforming growth facpopulation. Am $\mathcal{F}$ Med Genet 1995;57:548-51.

17 Dixon M J, Garner J, Ferguson MWJ. Immunolocalisation of epidermal growth factor (EGF), EGF receptor and of epidermal growth factor (EGT), EGF transforming growth factor alpha (TGFa) during murine palatogen

18 Fraser FC, Pashayan H. Relation of face shape to susceptibility to congenital cleft lip (a preliminary report). $\mathcal{\exists M e d}$ Genet 1970;7:112-17.

19 Coccaro PJ, D'Amico R, Chavoor A. Craniofacial morphology of parents with and without cleft lip and palate children. Cleft Palate $₹$ 1972;9:28-42.

20 Shibasaki Y, Ohtsuka S. A cephalometric study on craniofacial morphology of parents of children with cleft lip and palate. F Stomatol Soc fapan 1978;3:31-43.

21 Nakasima A, Ichinose M. Characteristics of craniofacial structures in parents of children with cleft lip and/or palate. Am $\mathcal{\text { Orthod }} 1983 ; 84: 140-6$.

22 Nakasima A, Ichinose $M$. Size of the cranium in parents and their children with cleft lip. Cleft Palate 7 1984:21:193-203.

3 Moir child the parents of children with orofacial clefting. $\mathrm{Br} \mathcal{F}$ Oral Maxillofac Surg (in press).

24 Sambrook J, Fritsch EF, Maniatis T. Molecular cloning. A laboratory manual. 2nd ed. Vol 1. New York: Cold Spring Laboratory Press, 1989.
25 Qian JF, Feingold J, Stoll C, May E. Transforming growth factor-alpha: characterisation of the BamHI, RsaI, TaqI polymorphic regions. Am f Hum Genet 1993;53:16875.

26 Houston WJB. A comparison of the reliability of measurement of cephalometric radiographs by tracings and direct digitization. Swed Dent $\mathcal{F}$ Suppl 1982;15:99-103.

27 Mossey PA, McColl JH, Stirrups DRS. Differentiation between cleft lip with or without cleft palate and isolated cleft palate using parental cephalometric parameters. Cleft Palate Craniofac F 1997;34:1-10.

28 Woolf B. On estimating the relationship between blood group and disease. Ann Hum Genet 1955;19:251-3.

29 Ferguson MWJ. Craniofacial malformations: towards a molecular understanding. Nat Genet 1993;6:329-30.

30 Spielman RS, McGinnis RE, Ewens WJ. Transmission test for linkage disequilibrium: the insulin gene region and insulin-dependent diabetes mellitus (IDDM). $\mathrm{Am} \mathcal{F} \mathrm{Hum}$ Genet 1993;52:506-16.

31 Falk CT, Rubinstein P. Haplotype relative risks: an easy reliable way to construct a proper control sample for risk calculations. Ann Hum Genet 1987;51:227-33.

32 Terwilliger JD, Ott J. A haplotype-based relative risk statistic. Hum Hered 1992;42:337-46.

33 Singh GD, McNamara JA, Lozanoff S. Morphometry of the cranial base in subjects with class III malocclusion. F Dent Res 1997;76:694-703. 